\title{
VIABILIDADE DE BACTÉRIAS (STARTER E PROBIÓTICAS) EM BEBIDAS ELABORADAS COM IOGURTE E POLPA DE MANGA
}

\section{Viability of bacteria (starter and probiotics) in beverages made with yogurt and mango pulp}

\author{
Paula de Paula Menezes Barbosa ${ }^{1 *}$, Darlila Aparecida Gallina ${ }^{2}$
}

\begin{abstract}
RESUMO
Este trabalho teve como objetivo desenvolver duas formulações de bebida probiótica do tipo smoothie com iogurte e polpa de manga (F1 e F2), bem como avaliar a viabilidade dos microrganismos, a qualidade higiênico sanitária e as características físico-químicas ( $\mathrm{pH}$, acidez e sinérese) das bebidas ao longo de 30 dias de estocagem refrigerada. F1 foi preparada com adição de $30 \%$ de polpa de manga e $10 \%$ de açúcar ao iogurte probiótico e F2 foi adicionada de $40 \%$ de polpa e $8 \%$ de açúcar. A qualidade higiênico-sanitária foi satisfatória, e as amostras seguras para consumo. As amostras não diferiram entre si quanto ao $\mathrm{pH}$, acidez titulável, sinérese e viabilidade dos microrganismos, ao longo da estocagem refrigerada, portanto, os níveis de açúcar e polpa não influenciaram significativamente as formulações. Os níveis de probióticos se mantiveram dentro da dose considerada terapêutica. Portanto, as bebidas podem ser consideradas um veículo apropriado para incorporação de probióticos e um novo produto funcional poderá ser disponibilizado para o mercado.

Palavras-chave: Bifidobacterium spp., viabilidade microbiológica, leite fermentado, polpa de frutas, smoothie.
\end{abstract}

\begin{abstract}
The study aimed to develop two formulations (F1 and F2) of probiotic mango

1 Universidade Estadual de Campinas (UNICAMP), Faculdade de Engenharia de Alimentos (FEA), Rua Monteiro Lobato, 80, Cidade Universitária Zeferino Vaz, 13083-862, Campinas, SP, Brasil. E-mail: paulamenezesbarbosa@gmail.com

2 Instituto de Tecnologia de Alimentos (ITAL), Campinas, SP, Brasil.

* Autor para correspondência.
\end{abstract}


smoothie with fermented milk, and to evaluate the microbiological viability and physicochemical ( $\mathrm{pH}$, acidity and desorption) characteristics under refrigerated storage. The formulation F1 was prepared with addition of $30 \%$ of mango pulp and $10 \%$ of sugar, and in F2 was added $40 \%$ of pulp and $8 \%$ of sugar. The hygienicsanitary quality was satisfactory, and the samples were safe for consumption. The samples did not differ in $\mathrm{pH}$, titratable acidity, syneresis and viability of the microorganisms along the refrigerated storage, therefore, the sugar and pulp levels did not significantly influence the formulations. Probiotic levels remained within the dose considered therapeutic. Therefore, these beverages F1 and F2 may be considered appropriate vehicles for incorporation of probiotics and a new functional product may be made available to the market.

Keywords: Bifidobacterium spp, microbial viability, fermented milk, fruit pulp, smoothie.

\section{INTRODUÇÃO}

Nos últimos tempos, os alimentos funcionais têm se destacado, devido aos seus benefícios à saúde além das funções nutricionais básicas. Atualmente, as bebidas são a categoria de alimentos funcionais mais ativas, devido à conveniência e demanda do consumidor em relação à embalagem, distribuição e estocagem (CORBO et al., 2014). Dentre as inovações em produtos funcionais, destacam-se os alimentos contendo probióticos, cujos benefícios estão relacionados ao equilíbrio da microbiota intestinal, à melhor absorção de nutrientes, a regulação do sistema imune, a prevenção de doenças inflamatórias do intestino, a diminuição de alergias, entre outros benefícios (KAUR et al., 2014; SANTIAGO-LÓPEZ et al., 2015).

Probióticos são microrganismos vivos que quando administrados em quantidades adequadas conferem benefícios à saúde do hospedeiro (FAO/WHO, 2001). Leite e produtos lácteos são excelentes veículos para estes microrganismos, sendo principalmente incorporados em iogurtes, queijos e sorvetes. No entanto, para conferir benefícios à saúde, as bactérias probióticas devem chegar ao intestino vivas e em quantidades suficientes, em torno de 6 a 7 log UFC/g (KUMAR;
KUMAR, 2016). Alguns autores sugerem níveis de probióticos de $10^{6} \mathrm{UFC} / \mathrm{mL}$ ou entre $10^{7}$ e $10^{8} \mathrm{UFC} / \mathrm{mL}$ para atingir níveis terapêuticos. Já a Federação Internacional de Laticínios (IDF) recomenda uma quantidade mínima de $10^{7}$ UFC por $g$ de produto consumido (LOURENS-HATTINGH; VILJOEN, 2001; KAILASAPATHY et al., 2008; DIAS et al., 2013; KAUR et al., 2014). Estes números requeridos, no entanto, podem variar de espécie para espécie, e mesmo entre estirpes dentro de uma mesma espécie. Contudo, a viabilidade dos probióticos na matriz alimentar está relacionada a diferentes fatores, como: pH, ácidos orgânicos, temperatura de armazenamento, níveis de oxigênio, presença de microrganismos e inibidores (KAILASAPATHY et al., 2008; TRIPATHI; GIRI, 2014).

O iogurte é um alimento convencional, já conhecido por suas propriedades terapêuticas, nutricionais e sensoriais. É obtido através da fermentação do leite, em que se utilizam as bactérias Lactobacillus delbrueckii subsp. bulgaricus e Streptococcus thermophilus. Nos últimos anos, iogurtes têm sido reformulados para incluírem estirpes de L. acidophilus e espécies de Bifidobacterium em adição aos microrganismos convencionais do iogurte. O bio-iogurte é um iogurte que 
contém microrganismos probióticos vivos, cuja presença pode proporcionar a alegação de efeitos benéficos para a saúde, sendo um veículo potencial pelo qual os consumidores podem tomar células probióticas (LOURENSHATTINGH; VILJOEN, 2001).

Verifica-se uma tendência em fortificar produtos lácteos com frutas, no intuito de melhorar o valor nutricional e sensorial (KAILASAPATHY et al., 2008). Algumas pesquisas sugerem que o suco de frutas poderia servir como um bom meio para ingredientes funcionais, como os probióticos (NAZZARO et al., 2008). O uso de sucos e polpas de frutas como ingredientes no desenvolvimento de novos produtos lácteos está de acordo com a tendência de consumo de alimentos saudáveis e que, ao mesmo, se mostram diferenciados por suas qualidades sensoriais (KUSKOSKI et al., 2006). As bebidas denominadas smoothies são originariamente elaboradas com uma mistura batida de polpa de frutas frescas e/ ou hortaliças, em que podem ser adicionados outros ingredientes como água, leite, iogurte, sorvete, etc (KEENAN et al., 2010).

Frutas e vegetais são ricos em compostos bioativos, como vitaminas, compostos antioxidantes e fibras (MELO et al., 2008; NAZZARO et al., 2008). Entre as frutas tropicais, a manga (Mangifera indica L.) está entre as mais apreciadas e consumidas. É considerada uma boa fonte de compostos benéficos à saúde, como: vitaminas (B2, B3 e C), minerais (cálcio, fósforo, ferro) e antioxidantes como ácido ascórbico, carotenóides e compostos fenólicos (RANGELMARRÓN et al., 2011; PALAFOX-CARLOS et al., 2012).

Novos produtos e matérias-primas para aplicação de probióticos são a principal área de pesquisa e desenvolvimento para o mercado de alimentos funcionais. As inovações tecnológicas atuais incluem a busca de soluções para os problemas de estabilidade e viabilidade de probióticos em novas matrizes alimentares, como frutas, cereais e outros vegetais (FARNWORTH et al., 2007). Assim sendo, pesquisas são importantes no desenvolvimento de novos alimentos probióticos, com o intuito de aumentar o número de produtos com funcionalidade no mercado e oferecer novas opções para os consumidores (GRANATO et al., 2010).

Portanto, o presente trabalho objetivou elaborar duas bebidas tipo smoothie contendo iogurte probiótico e polpa de manga a fim de avaliar a viabilidade dos microrganismos em novas matrizes alimentares. Para tal formulações de smoothie probiótico de manga foram elaboradas e analisadas quanto ao $\mathrm{pH}$, acidez titulável, sinérese, qualidade higiênico-sanitária e viabilidade de microrganismos da cultura starter e probióticos nas bebidas durante trinta dias de estocagem refrigerada, visando o estudo de uma nova matriz alimentar para incorporação de probióticos.

\section{MATERIAL E MÉTODOS}

\section{Culturas starter e probiótica}

Na elaboração das bebidas tipo smoothie foram empregadas as culturas comerciais: starter de iogurte ( $S$. thermophilus e $L$. delbrueckii ssp. bulgaricus - JOINTEC X3, CSL) e probiótica mista (Bifidobacterium longum, B. infantis e B. breve-BIFI, CSL), ambas cedidas pela empresa Kerry do Brasil. A ativação das culturas liofilizadas foi realizada de acordo com as instruções do fabricante. As culturas foram aliquotadas e estocadas a $-20^{\circ} \mathrm{C}$ para posterior uso.

\section{Elaboração das bebidas tipo smoothie}

Duas formulações de bebida probiótica tipo smoothie foram elaboradas (Figura 1). Inicialmente, preparou-se o iogurte probiótico com leite em pó desnatado (LPD) 
reconstituído (14\%) e açúcar. Esta mistura foi tratada termicamente à $85^{\circ} \mathrm{C}$ por $30 \mathrm{mi}$ nutos em banho termostatizado e em seguida resfriada à $42-44{ }^{\circ} \mathrm{C}$ e adicionada das culturas starter e probiótica. A fermentação foi conduzida até $\mathrm{pH} 4,8-4,7$. Ao fim da fermentação, o iogurte foi resfriado à $20-25{ }^{\circ} \mathrm{C} \mathrm{e}$ em seguida foi feita a quebra do coágulo em fluxo laminar. A primeira formulação (F1) foi adicionada de polpa de manga pasteurizada na concentração 70/30 (iogurte/polpa, m/m), açúcar $(10 \%)$ e sorbato de potássio $(0,03 \%)$. A segunda formulação (F2) foi preparada do mesmo modo, diferindo na concentração de polpa de manga, adicionada na proporção 60/40 (iogurte/polpa, m/m) e na concentração de açúcar (8\%). Ambas foram elaboradas em duplicata e estocadas em câmara fria a 8 $\pm 2{ }^{\circ} \mathrm{C}$ por 30 dias.

Após a fabricação, as bebidas foram avaliadas durante a estocagem (1, 15 e 30 dias) quanto a qualidade higiênico sanitária (bolores e leveduras, coliformes a $30{ }^{\circ} \mathrm{C} \mathrm{e} 45^{\circ} \mathrm{C}$ ), $\mathrm{pH}$, acidez titulável, sinérese e a viabilidade dos microrganismos (contagem seletiva de
S. thermophilus, L. delbrueckii ssp. bulgaricus e bifidobactérias).

\section{Avaliações físico-químicas}

$\mathrm{O} \mathrm{pH}$ das bebidas foi mensurado com pHmetro digital (Micronal B-375). A acidez titulável foi determinada por titulação com solução de hidróxido de sódio $0,1 \mathrm{M}$ até $\mathrm{pH}$ 8,3 (IAL, 2008), com resultado expresso em g de ácido láctico por $100 \mathrm{~g}$ da bebida. Para determinar a sinérese das bebidas, alíquotas de $10 \mathrm{~mL}$ foram estocadas a $8 \pm 2{ }^{\circ} \mathrm{C}$ em tubos de ensaio estéreis de fundo cônico de $15 \mathrm{~mL}$, realizando-se a medida da dessoragem ou separação do soro na superfície do produto, em centímetros (CAETANO SILVA et al., 2010).

\section{Avaliações microbiológicas}

A amostragem foi realizada de forma asséptica (câmara de fluxo laminar) e alíquotas de $1 \mathrm{~mL}$ das amostra foram transferidas para tubos com água peptonada estéril $0,1 \%$ para análise.
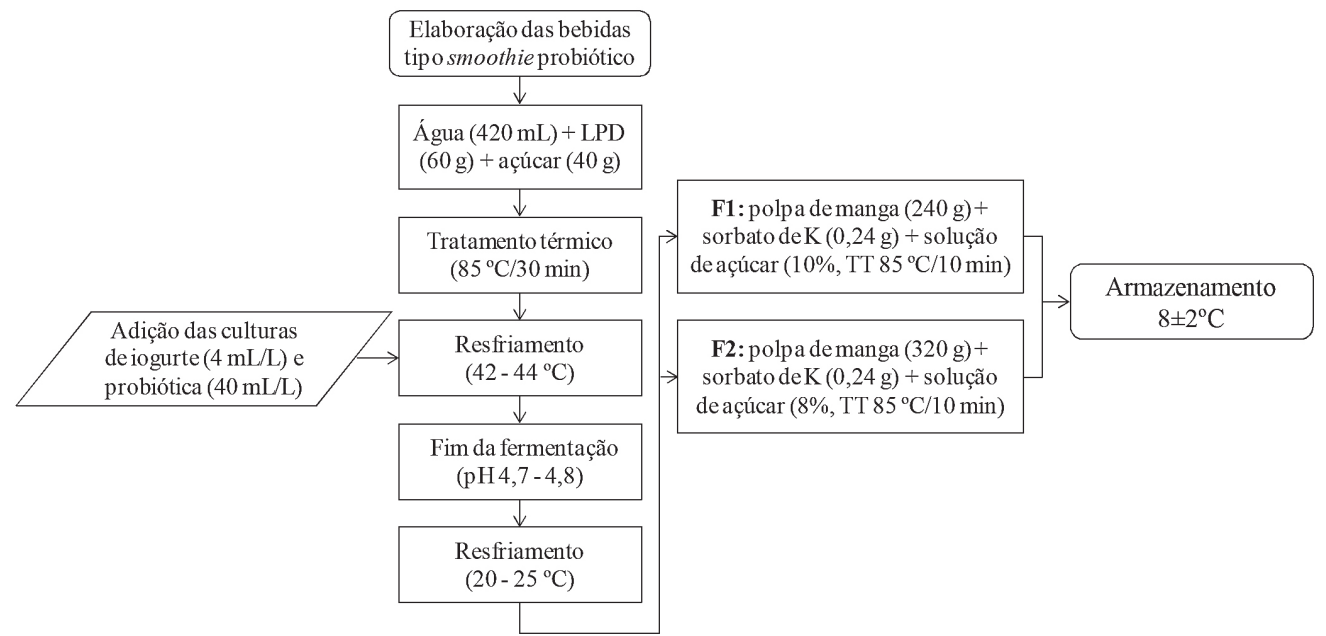

TT: tratamento térmico

Figura 1 - Fluxograma de fabricação da bebida probiótica tipo smoothie 
Foram empregados meios seletivos e condições de incubação adequadas para favorecer o crescimento dos microrganismos de interesse. Para a quantificação de $L$. bulgaricus, utilizou-se o ágar MRS (Difco) acidificado $(\mathrm{pH}=5,4)$, com incubação a 37 $\pm 1{ }^{\circ} \mathrm{C}$ por $72 \mathrm{~h}$ (FRANK; YOUSEF, 2004). A contagem de $S$. thermophilus foi realizada em meio ágar M17 (Difco) suplementado com solução de glicose (5\%), com incubação a $37 \pm 1{ }^{\circ} \mathrm{C}$ por $48 \mathrm{~h}$ (FRANK; YOUSEF, 2004). Os microrganismos do gênero Bifidobacterium spp. foram quantificados em ágar MRS suplementado com cloreto de lítio $(0,1 \%)$, L-cisteína $(0,05 \%)$ e dicloxacilina $(0,5 \mathrm{mg} / \mathrm{L})$, com incubação a $37 \pm 1{ }^{\circ} \mathrm{C}$ por $72 \mathrm{~h}$, de acordo com a metodologia descrita no boletim técnico P-12 da Chr-Hansen, com adaptações segundo o IDF (2007). Utilizou-se o plaquemento por profundidade e incubação em anaerobiose. As colônias obtidas nos diferentes meios seletivos foram verificadas com a coloração de Gram para confirmação da morfologia dos grupos avaliados.

A contagem de coliformes a $30{ }^{\circ} \mathrm{C}$ e a $45^{\circ} \mathrm{C}$ foi determinada pelo método do número mais provável (NMP), utilizando caldo lauril sulfato triptose (LST), como teste presuntivo, com incubação a $30 \pm 1{ }^{\circ} \mathrm{C}$, por $24 \pm 2$ horas (ISO 4831, 2006). Para confirmação da presença de coliformes, alíquotas de tubos de LST com crescimento microbiano e produção de gás foram transferidas para tubos de caldo verde brilhante $2 \%$ (VB, Difco) e caldo Escherichia coli (EC, Difco). Os tubos de VB foram incubados a $30 \pm 1{ }^{\circ} \mathrm{C}$, por $24 \pm 2 \mathrm{~h}$, para confirmar a presença de coliformes a $30{ }^{\circ} \mathrm{C}$ e os tubos de EC foram incubados por até 48 \pm 2 horas à $44 \pm 1^{\circ} \mathrm{C}$, para a confirmação da presença de coliformes termotolerantes (ISO 7251, 2005).

Os bolores e leveduras foram enumerados empregando-se o ágar dicloran rosa bengala cloranfenicol (DRBC), com incubação por 5 dias a $25 \pm 1{ }^{\circ} \mathrm{C}$, segundo a metodologia descrita por Frank; Yousef (2004).

\section{Análise estatística}

Os fatores $\mathrm{pH}$, acidez titulável, sinérese e contagem de microrganismos das duas formulações das bebidas smoothie foram avaliados ao longo do período de 30 dias de estocagem refrigerada. O teste-t ao nível de $5 \%$ de probabilidade foi empregado para comparação das formulações no mesmo tempo de estocagem. Enquanto que, o teste de análise de variância (ANOVA) seguido pelo teste Tukey, foram empregados para avaliar o efeito do tempo de armazenamento sobre as amostras. Os dados foram analisados através do software Minitab, versão 16.1.1.

\section{RESULTADOS E DISCUSSÃO}

\section{Análises físico-químicas}

A polpa de manga empregada na elaboração das bebidas apresentava $\mathrm{pH}$ de 4,0; acidez de 0,41 g de ácido cítrico em $100 \mathrm{~g}$ de polpa e 14,5 de ${ }^{\circ}$ Brix. Estes valores estão em conformidade com a legislação vigente para polpa de manga (BRASIL, 2000), a qual estabelece $\mathrm{pH}$ entre 3,3 e 4,5; acidez mínima de $0,32 \mathrm{~g}$ de ácido cítrico/ $100 \mathrm{~g}$ de polpa e teor de sólidos solúveis totais mínimo de $11^{\circ}$ Brix.

A Figura 2 apresenta a média dos resultados obtidos quanto ao $\mathrm{pH}$ e a acidez titulável das bebidas durante 30 dias sob refrigeração. Pode-se observar um aumento significativo $(\mathrm{p} \leq 0,05)$ na acidez das bebidas (0,5 g a $0,6 \mathrm{~g}$ por $100 \mathrm{~g}$ de produto), ao longo do período de estocagem, e uma diminuição dos valores de $\mathrm{pH}(4,65$ a 4,51), o que normalmente se observa durante a estocagem de produtos lácteos fermentados (GALLINA et al., 2012). O aumento da acidez ao longo da estocagem se justifica, pois, mesmo sob refrigeração, as bactérias continuam fermentando lentamente a lactose e produzindo ácido láctico, diminuindo o $\mathrm{pH}$ destes produtos. Dentre as bactérias lácticas do iogurte, o L. delbrueckii ssp. 

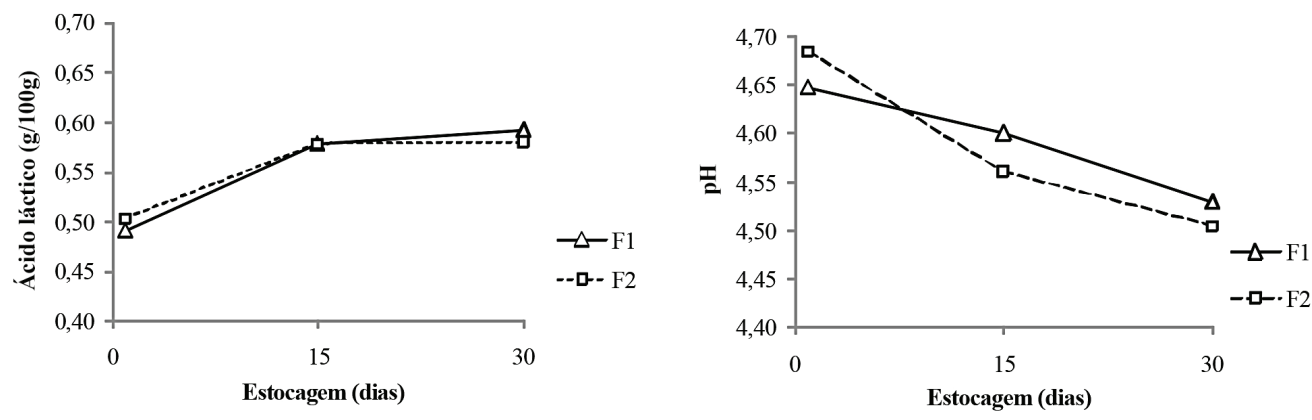

Figura 2 - Mudanças nos valores $\mathrm{pH}$ e de acidez ao longo de 30 dias de estocagem refrigerada $\left(8 \pm 2{ }^{\circ} \mathrm{C}\right)$ das duas formulações de bebida probiótica smoothie de manga

bulgaricus é o principal responsável pela diminuição do $\mathrm{pH}$ durante a vida de prateleira (KAILASAPATHY et al., 2008). No entanto, ao comparar o $\mathrm{pH}$ e a acidez das formulações em um mesmo tempo de estocagem, as bebidas F1 e F2 não diferiram significativamente entre si $(p>0,05)$. Isto demonstra que as concentrações de açúcar e polpa de manga aplicadas não afetaram de forma significativa o pH e a acidez titulável das duas bebidas, já que as amostras se comportaram de forma similar em cada período de estocagem.

Outros trabalhos que estudaram a adição de polpa de fruta em iogurte também verificaram aumento da acidez e redução do $\mathrm{pH}$ ao longo do armazenamento destes produtos (KAILASAPATHY et al., 2008; GALLINA et al., 2012; HOSSAIN et al., 2012). A importância do pH e acidez está relacionada com as suas características sensoriais, assim como, a viabilidade dos microrganismos presentes no produto. Verifica-se que as bebidas F1 e F2 são produtos com menor acidez que os iogurtes tradicionais, que devem ter entre 0,6 e 1,5 g ácido láctico/100 g de produto. Portanto, estas bebidas podem ser uma matriz alimentar mais favorável para a manutenção da viabilidade dos microrganismos probióticos.

As sinéreses das bebidas F1 e F2 podem ser observadas na Figura 3. Não foi observada diferença significativa $(\mathrm{p}>0,05)$ entre as formulações F1 e F2 no mesmo período de tempo. Porém, observa-se um aumento significativo $(\mathrm{p} \leq 0,05)$ na taxa de dessoragem, ou sinérese das bebidas após o $15^{\circ}$ dia de estocagem refrigerada.

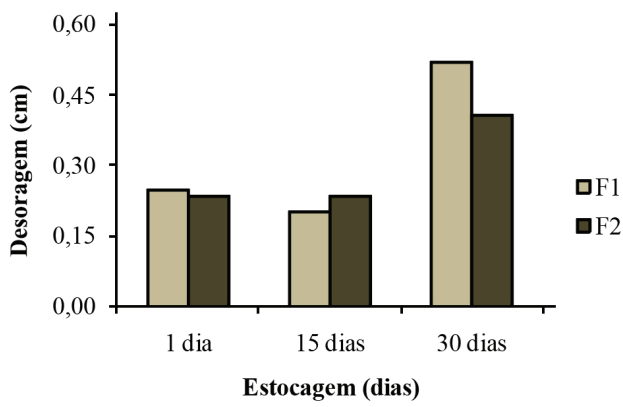

Figura 3 - Sinérese das formulações de bebida probiótica smoothie de manga durante 30 dias de estocagem refrigerada $\left(8 \pm 2{ }^{\circ} \mathrm{C}\right)$

O processo de dessoragem ou sinérese do iogurte é um atributo importante na aceitação do produto pelo consumidor. Este fenômeno se caracteriza pela liberação espontânea de água do gel, podendo ser intensificado por mudanças na temperatura, $\mathrm{pH}$ e por fatores mecânicos, como vibração (CAETANO SILVA et al., 2010). Conforme foi verificado, ocorreu um aumento significativo da acidez e redução do $\mathrm{pH}$ durante a estocagem, o que 
pode justificar o aumento na sinérese das bebidas ao longo da estocagem.

\section{Qualidade microbiológica}

A quantificação de bolores e leveduras e coliformes são importantes parâmetros para a qualidade higiênico-sanitária de um produto. As bebidas F1 e F2 foram analisadas quanto à presença destes microrganismos após um dia de fabricação e os resultados estão apresentados na Tabela 1.

Verifica-se que a contagem dos microrganismos está dentro dos parâmetros exigidos para leites fermentados, pois na ausência de uma legislação específica para smoothies, esta é a que mais se assemelha às formulações elaboradas. Os resultados microbiológicos obtidos demonstram cuidados de manipulação para a elaboração das bebidas e uma boa qualidade higiênico-sanitária das bebidas, podendo ser consideradas seguras para o consumo.

\section{Viabilidade das culturas de iogurte e probiótica}

As contagens de $S$. thermophilus (cocos gram positivos) estão apresentadas na Figura 4, e variaram entre 8,66 e 8,83 $\log \mathrm{UFC} / \mathrm{mL}$. Observou-se uma pequena redução deste microrganismo ao longo do armazenamento das bebidas, porém essa diminuição não foi significativa $(\mathrm{p}>0,05)$. Da mesma forma, entre as amostras F1 e F2 não houve diferença significativa $(\mathrm{p}>0,05)$ nas contagens para um mesmo período de tempo. Portanto, ambas as formulações propostas foram matrizes favoráveis para a manutenção da viabilidade do $S$. thermophilus durante 30 dias de estocagem refrigerada.

Tabela 1 - Perfil microbiológico das bebidas probióticas smoothie de manga (F1 e F2) comparadas com os padrões exigidos pela legislação para leites fermentados (BRASIL, 2007)

\begin{tabular}{cccc}
\hline $\begin{array}{c}\text { Microrganismos } \\
\text { Coliformes a } 30{ }^{\circ} \mathrm{C}\end{array}$ & $\mathrm{F} 1$ & $\mathrm{~F} 2$ & Legislação \\
\hline $\begin{array}{c}(\mathrm{NMP} / \mathrm{mL}) \\
\text { Coliformes a } 45^{\circ} \mathrm{C}\end{array}$ & $<0,3$ & $<0,3$ & Máximo de $10^{2}$ \\
\hline $\begin{array}{c}(\mathrm{NMP} / \mathrm{mL}) \\
\text { Bolores e Leveduras } \\
(\mathrm{UFC} / \mathrm{mL})\end{array}$ & $<0,3$ & $<0,3$ & Máximo de $10^{1}$ \\
\hline
\end{tabular}
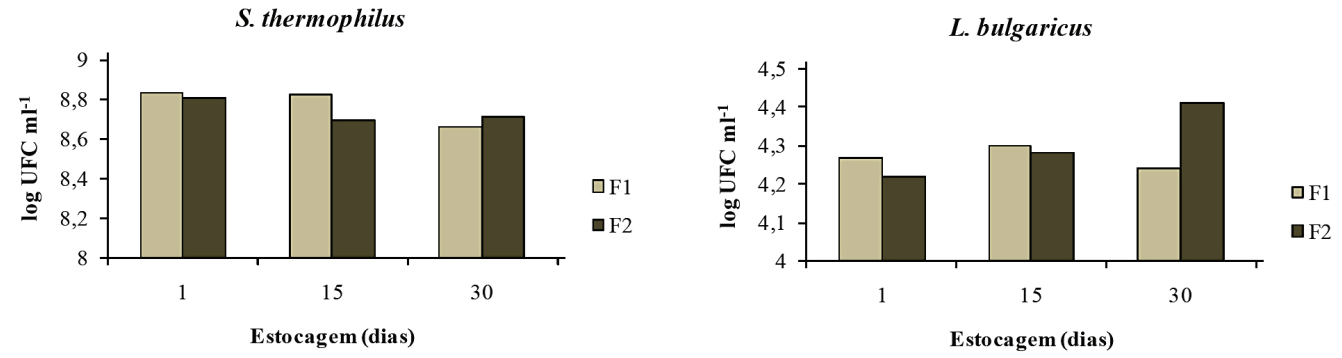

Figura 4 - Contagem de $S$. thermophilus e de L. bulgaricus nas bebidas F1 e F2, ao longo da estocagem 
Com relação à contagem de $L$. delbrueckii ssp. bulgaricus (bacilos gram positivos), as contagens variaram entre 4,22 e 4,41 $\log \mathrm{UFC} / \mathrm{mL}$. Diferentemente do que foi observado na contagem de $S$. thermophilus, observou-se um pequeno aumento na população de L. delbrueckii ssp. bulgaricus em F2 ao longo do armazenamento $(0,19 \log \mathrm{UFC} / \mathrm{mL})$, porém esse aumento não foi significativo $(\mathrm{p}>0,05)$. $\mathrm{O}$ aumento na população deste microrganismo pode ser atribuído à redução do $\mathrm{pH}$ dos smoothies ao longo da estocagem, uma vez que outros autores já relataram que a queda do $\mathrm{pH}$ pode favorecer o crescimento de L. delbrueckii ssp. bulgaricus em iogurtes (FARIAS et al., 2016).

Ao comparar as bebidas F1 e F2 quanto as contagens de L. delbrueckii ssp. bulgaricus, verifica-se que estas não diferiram entre si $(p>0,05)$ no mesmo período de tempo. No entanto, observa-se uma baixa contagem de L. delbrueckii ssp. bulgaricus nas formulações $(<4,5 \log \mathrm{UFC} / \mathrm{mL})$, inferior ao St. thermophilus. É desejável no final da fermentação uma proporção próxima a 1 entre eles. De acordo com Gallina et al. (2011) as contagens relativamente inferiores do $L$. bulgaricus em comparação às de St. thermophilus, pode indicar desbalanceamento dos microrganismos no fermento, ou que a fermentação foi interrompida em $\mathrm{pH}$ um pouco superior, onde o número de $L$. bulgaricus não se encontrava equivalente. No entanto, estas contagens podem favorecer a manutenção dos probióticos tendo em vista que o L. delbrueckii ssp. bulgaricus é um microrganismo acidificante (FARIAS et al., 2016), e o excesso de acidificação é indesejável e prejudicial às bifidobactérias. A legislação vigente preconiza para iogurtes a contagem mínima de bactérias láticas totais de $10^{7}$ UFC por g de produto (BRASIL, 2007). Nas bebidas elaboradas, apesar das baixas contagens de L. delbrueckii ssp. bulgaricus as contagens totais de bactérias lácticas se mantiveram dentro deste limiar desejável durante todo o período de estocagem.

A viabilidade da cultura probiótica de Bifidobacterium spp. (gram positivas) ao longo da estocagem das bebidas (F1 e F2) está apresentada na Figura 5, variando entre 6,27 e 6,81 log UFC/mL. Verifica-se uma redução nas contagens deste microrganismo de 0,19 e $0,54 \log U F C / m L$, em F1 e $\mathrm{F} 2$ respectivamente, ao longo do período de estocagem. Contudo, essa redução apenas é significativa $(\mathrm{p} \leq 0,05)$ para $\mathrm{F} 2$, a partir de 15 dias de estocagem.

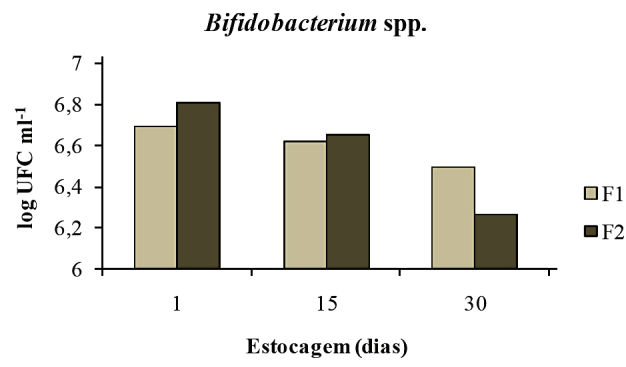

Figura 5 - Contagem de Bifidobacterium spp. ao longo da estocagem e coloração de gram das colônias

Estudos relataram que a viabilidade de probióticos em alimentos pode ser afetada por diferentes fatores, como a presença de alguns ácidos orgânicos e baixos valores de pH. Lankaputhra et al. (1996) enfatizaram que o $\mathrm{pH}$ do iogurte abaixo de 4,30 afeta grandemente a viabilidade das bactérias probióticas, sendo as bifidobactérias sensíveis ao $\mathrm{pH}$ de sucos de frutas ( $\mathrm{pH}$ estão entre 3 e 4 ). No entanto, a natureza dos ácidos orgânicos presente no alimento pode influenciar negativamente no desenvolvimento dos probióticos. Kailasapathy et al. (2008) avaliaram a adição de manga (5 g em 100 g) em iogurtes probióticos, porém não observaram redução da viabilidade destes microrganismos, possivelmente devido à menor concentração de fruta adicionada, quando comparado a 
formulação F2. Portanto, o maior teor de polpa de manga na formulação F2 pode ter afetado a viabilidade dos probióticos após 15 dias de estocagem, possivelmente devido à maior concentração de ácidos orgânicos nesta matriz alimentar.

Já quando comparamos as duas formulações, F1 e F2, verifica-se que estas não diferiram entre si $(p>0,05)$ no mesmo período de tempo, mantendo ao final do período da estocagem contagens em torno de $6 \log \mathrm{UFC} / \mathrm{mL}$. Gallina et al. (2011) também verificaram contagens de bifidobactérias de $6 \log$ UFC/ $\mathrm{mL}$ para iogurte probiótico adicionado de FOS durante 28 dias de estocagem refrigerada. Gallina et al. (2012) observaram que a viabilidade da cultura probiótica em uma bebida desenvolvida com uma mistura $(50 / 50 \%)$ de leite fermentado (com cultura de iogurte e bifidobactérias) e polpa de goiaba, com e sem a adição de FOS, se manteve com valores entre $10^{6}$ e $10^{7} \mathrm{UFC} / \mathrm{mL}$, durante 30 dias de estocagem refrigerada mesmo em condição desfavorável de $\mathrm{pH}(4,4)$. Vários autores propõem que a dose diária mínima da cultura probiótica considerada terapêutica seja de $10^{8}$ a $10^{9}$ UFC, o que corresponde ao consumo de $100 \mathrm{~g}$ de produto contendo $10^{6}$ a $10^{7}$ UFC/g (LOURENS-HATTINGH; VILJOEN, 2001; KAILASAPATHY et al. 2008; DIAS et al., 2013; KAUR et al., 2014). Portanto, as duas bebidas smoothie elaboradas (F1 e F2) apresentaram contagens que atendem esta recomendação.

\section{CONCLUSÕES}

As formulações F1 e F2 de bebidas tipo smoothie probiótico de manga não diferem entre si $(\mathrm{p}>0.05)$ quanto aos parâmetros $\mathrm{pH}$, acidez titulável, sinérese e contagem de microrganismos ( $S$. thermophilus, $L$. bulgaricus e bifidobactérisas ssp.), em um mesmo tempo estocagem (1, 15 ou 30 dias). Além disso, nota-se que os dois níveis de açúcar $(8 \%$ e $10 \%)$ e polpa de manga $(30 \%$ e $40 \%$ ) empregados, não afetam de forma significativa as características das bebidas.

Desta forma, os resultados apresentados nos permitem concluir que as novas formulações de smoothie probiótico de manga são matrizes favoráveis para a manutenção da viabilidade dos microrganismos (bactérias starter e probióticas) durante toda a estocagem refrigerada, em níveis estabelecidos pela legislação. Neste contexto, este trabalho contribui para o desenvolvimento de novos produtos funcionais, pois as formulações de smoothie são veículos satisfatórios para a incorporação de bactérias probióticas podem ser consideradas novas matrizes alimentares para a adição destas bactérias.

\section{AGRADECIMENTOS}

Ao Conselho Nacional de Desenvolvimento Científico e Tecnológico (CNPq) pelo financiamento do projeto.

\section{REFERÊNCIAS}

BRASIL. Ministério da Agricultura, Pecuária e Abastecimento. Instrução Normativa $n^{\circ} 01$, de 7 de janeiro de 2000. Regulamento técnico geral para fixação dos padrões de identidade e qualidade para polpa de fruta. Diário Oficial da República Federativa do Brasil. Brasília, DF, jan. 2000.

BRASIL. Ministério da Agricultura, Pecuária e Abastecimento. Instrução Normativa $\mathrm{n}^{\mathrm{o}} 46$, de 23 de outubro de 2007. Adota o Regulamento Técnico de Identidade e Qualidade de Leites Fermentados. Diário Oficial da República Federativa do Brasil, Brasília, DF, 24 out. 2007.

CAETANO SILVA, M. E. et al. Estudo da viabilidade tecnológica da aplicação de coacervado de proteínas de soro de leite com 
carboximetil celulose em iogurte probiótico. Brazilian Journal of Food and Technology, Campinas, v. 13, n. 1, p. 30-37, 2010.

CORBO, M. R. et al. Functional Beverages: The Emerging Side of Functional Foods Commercial Trends, Research, and Health Implications. Comprehensive Reviews in Food Science and Food Safety, v. 13, p. 1192-1206, 2014.

DIAS, M. L. L. A. et al. Phisicochemical, sensory, and microbiological evaluation and development of symbiotic fermented drink. Food Science and Technology, v. 33, n. 4, p. 805-811, 2013.

FARIAS, P. K. S. et al. Contagem de bactérias lácticas em iogurtes comerciais. Revista Brasileira de Ciências Agrárias, v. 8, n. 3, p. 38-44, 2016.

FARNWORTH, E. R. et al. bacteria and bifidobacteria in a soy yogurt formulation. International Journal of Food Microbiology, v. 116, p. 174-181, 2007.

FOOD AND AGRICULTURE ORGANIZATION OF THE UNITED NATIONS AND WORLD HEALTH ORGANIZATION REPORT - FAO/WHO. Report of a joint FAO/WHO evaluation of health and nutritional properties of probiotics in food including powder milk and live lactic acid bacteria. Córdoba, Argentina, 2001, 34 p. Disponível em: <ftp://ftp.fao.org/es/esn/ food/probio_report_en.pdf $>$. Acesso em: 20 mar. 2017.

FRANK, J. F.; YOUSEF, A. E. Tests for groups of microorganisms. In: WEHR, H. M.; FRANK, J. F. (Ed.). Standard Methods for the examination of dairy products (17th ed.). American Public Health Association, Washington, D.C., 2004, p. 227-247.
GALlinA, D. A. et al. Caracterização de bebida obtida a partir de leite fermentado simbiótico adicionado de polpa de goiaba e avaliação da viabilidade das bifidobactérias. Revista do Instituto de Laticínios Cândido Tostes, v. 67, n. 386, p. 45-54, 2012.

GALLINA, D. A. et al. Caracterização de leites fermentados com e sem adição de probióticos e prebióticos e avaliação da viabilidade de bactérias láticas e probióticas durante a vida-de-prateleira. Unopar Ciências Biológicas e da Saúde, v. 13, n. 4, p. 239-244, 2011.

GRANATO, D. et al. Probiotic dairy products as functional foods. Comprehensive reviews in food science and food safety, v. 9, p. 455470, 2010.

HOSSAIN, M. N. et al. Quality comparison and acceptability of yoghurt with different fruit juices. Jounal of Food Processing Technology, v. 3, n. 8:171, p. 1-5, 2012.

INTERNATIONAL DAIRY FEDERATION (IDF). Bulletin of the IDF $\mathbf{n}^{\mathbf{0}} \mathbf{4 1 1 / 2 0 0 7}$. Selective enumeration of bifidobacteria in dairy products: development of a standard method, 20 p., 2007.

INSTITUTO ADOLFO LUTZ - IAL. Leites e Fermentados - Determinação da acidez em ácido láctico. In: Métodos físico-químicos para análise de alimentos. Ed. 4, São Paulo: Instituto Adolfo Lutz, 2008. cap. 27, p. 879.

ISO 4831. THE INTERNATIONAL ORGANIZATION FOR STANDARDIZATION. Microbiology of food and animal feeding stuffs - Horizontal method for the detection and enumeration of coliforms Most probable number technique, 3rd Ed., 2006. 
KAILASAPATHY, K. et al. Survival of Lactobacillus acidophilus and Bifidobacterium animalis ssp. lactis in stirred fruit yogurts. Food Science and Technology, v. 41, n. 7, p. 1317-1322, 2008.

KAUR, A. et al. Probiotics and its health benefits. Journal of Global Biosciences, v. 3, n. 3, p. 686-693, 2014.

KEENAN, D. F. et al. Effect of thermal and high hydrostatic pressure processing on antioxidant activity and colour of fruit smoothies. Innovative Food Science and Emerging Technologies, v. 11, p. 551-556, 2010 .

KUMAR, A.; KUMAR, D. Development of antioxidant rich fruit supplemented probiotic yogurts using free and microencapsulated Lactobacillus. Jounal of Food Science and Technology, v. 53, n. 1, p. 667-675, 2016.

KUSKOSKI, E. M. et al. Frutos tropicais silvestres e polpas de frutas congeladas: atividade antioxidante, polifenóis e antocianinas. Ciência Rural, v. 36, n. 4, p. 1283-1287, 2006.

LANKAPUTHRA, W. E. V. et al. Evaluation of media for selective enumeration of Lactobacillus acidophilus and Bifidobacterium species. Food Australia, v. 48, n. 3, 113-118, 1996.

LOURENS-HATTINGH, A.; VILJOEN, B. C. Yogurt as probiotic carrier food.
International Dairy Journal, v. 11, p. 1-17, 2001.

MELO, E. A. et al. Capacidade antioxidante de frutas. Revista Brasileira de Ciências Farmacêuticas, v. 44, n. 2, p. 193-201, 2008.

NAZZARO, F. et al. Synbiotic potential of carrot juice supplemented with Lactobacillus spp. and inulin or fructooligosaccharides. Journal of the Science of Food and Agriculture, v. 88, p. 2271-2276, 2008.

PALAFOX-CARLOS, H. et al. Identification and quantification of major phenolic compounds from mango (Mangifera indica, cv. Ataulfo) fruit by HPLC-DADMS/MS-ESI and their individual contribution to the antioxidant activity during ripening. Food Chemistry, v. 135, p. 105-111, 2012.

RANGEL-MARRÓN, M. et al. Estimation of moisture sorption isotherms of mango pulp freeze-dried. International Journal of Biology and Biomedical Engineering, v. 5, p. 18-23, 2011.

SANTIAGO-LOPEZ, L. et al. The effects of consuming probiotic-fermented milk on the immune system: A review of scientific evidence. International Journal of Dairy Technology, v. 68, n. 2, p. 153-165, 2015.

TRIPATHI, M. K.; GIRI, S. K. Probiotic functional foods: Survival of probiotics during processing and storage. Journal of functional foods, v. 9, p. 225-241, 2014. 